Nigerian Journal of Physiological Sciences 22 (1-2): 117-121 CPhysiological Society of Nigeria, 2007

Available online/abstracted at http://www.biolineinternational.org.br/njps; www.ajol.info/journals.njps; www.cas.org

\title{
COMPARATIVE EVALUATION OF ACTIVE LEARNING AND THE TRADITIONAL LECTURES IN PHYSIOLOGY: A CASE STUDY OF 200 LEVEL MEDICAL LABORATORY STUDENTS OF IMO STATE UNIVERSITY, OWERRI.
}

\author{
U. S. B. ANYAEHIE, Ed. NWOBODO and C. J. NJOKU
}

\author{
Department Of Physiology, College Of Medicine and Heath Sciences, Imo State University, Owerri. \\ E-mail: ugobond@yahoo.com; ednwobodo@yahoo.com
}

\begin{abstract}
Summary: Currently, understanding of Physiology and disease patterns is undergoing a fundamental paradigm shift with attendant shift in education of health professionals worldwide towards active learning to encourage exploration of connections and their relationships. We introduced problem-based learning to Physiology teaching of medial laboratory students to confirm worldwide reports that active learning environments offer better learning opportunities over the traditional methods which is the predominant teaching method in Nigerian universities. Our findings indicate that Problem-based learning increases students' attendance/participation in classes and performance in examination. We recommend the integration of active learning into physiology curriculum of Nigerian Universities.
\end{abstract}

Key Words: Medical education, active learning, cohort, students

\section{Introduction}

Medical education is constantly undergoing revision and renewal in attempts to ensure appropriate depth and breadth of knowledge of basic and clinical sciences as well as provide an environment that encourages lifelong learning and integrative reasoning skills (Vari and Lencher, 2001). Knowledge and skills in biomedical sciences have reached a level which it is difficult to pass on to students in the usual 1-2 years of traditional lecture methods and are still expanding (Nshaho, 2005).Current science of learning and transfer of information has uncovered important principles for structuring learning experiences to enable people transfer what they have learnt in new settings, such that knowing is no longer the ability to remember and repeat information but being able to find and use it. The system of learning which enables people take control of their own learning has been described as 'active learning'. The focus in this type of learning is sense-making, self-assessment and reflection on what works and what needs improving on (Committee On Development in Science of Learning, 2004). This improves transfer of learning to new settings and events (Palinscar and Brown, 1984).

Physiology is part of the core curriculum of medical and allied medical training programmes in Nigeria. The medical learning objective project organized by the American Physiological Society and Association of Chairs of Departments of Physiology in 1998 constructed 682 individual physiology-learning objectives. (Available on: www.the.aps.org/education/medphys $\mathrm{obj} /$ medcor.com). Part of the recommendation is the introduction of new ways of teaching physiology to enable students to transfer the learning. Basic science teaching is fraught with special difficulties ranging from sustaining interest and clinical correlation (Nwobodo, 2005).

Problem-based learning (PBL) is a type of active learning in which a problem becomes a stimulus for learning experience .It originated at Mc Master University in Canada (Neufeld et al 1989) and now an exclusive learning method in many medical schools all over the world. It was initially promoted as an approach at developing problem solving skills (Barrows and Tamblyn, 1980) but now known to promote learning across subject domains (Norman and Schmidt, 1992).

What is problem-based learning $(P B L)$ :

PBL is a method of learning in which the students first encounter a problem followed by a systematic inquiry and reflection process (Barrows and Tamblyn, 1980). The problem stimulates students' activation and exploration 
of pre-existing knowledge and subsequent tutorguided discovery helps the student appreciate the edge of their knowledge. The goal is for students working in small groups with a facilitator (tutor) to learn to explore, choose, question, disagree and explain the science, basis and necessary connections, dynamic patterns and processes involved in a particular health related problem (Mennin, 2007). The characteristics of PBL are self-directed learning, elaboration, timely feedback and reflection. PBL also promotes working in groups and generate high levels of motivation and enthusiasm (Cross PK, 1987), such that knowledge acquired is retained for a longer time (Nshaho, 2005).

Today, there are as many variants of PBL as there are practitioners (Barrows, 1986; Dolmans et al, 2005), but what is vital is that they be grounded in current educational theory, having the characteristic principles and applications of PBL. Globally there is a trend towards introducing PBL in pre-clinical courses as is applicable in clinical courses, and much progress has been made in the USA with many medical schools using either PBL exclusively or a PBL/traditional lecture model. Seven papers at the 2001 American Physiological Society (APS) refresher course promoted this hybrid model (APS refresher course report, 2001). The progress in adopting this teaching method in Nigeria has been encouraging and was the focus of workshop presentations at the University of Nigeria College of Medicine (Nwobodo, 2005).

In this paper we report a comparative evaluation of the performances of students who received a hybrid traditional/PBL lectures (active learning) with those who were given the traditional lectures in a cardiovascular and respiratory physiology course.

\footnotetext{
Materials and method

Materials

The subjects were two consecutive second year medical laboratory students of College of Medicine and Health sciences, Imo State University, Owerri (groups A and B), admitted via Joint Matriculation Examination (JME). All lectures were given by the same lecturer.

Group A consisted of 126 students aged between 18-30 years (mean $=22$ ) who met our inclusion criteria and had traditional lectures series.
}

Group B was 168 students aged 17- 26 (mean =22) who had PBL sessions plus traditional lectures (PBL/traditional lecture model).

The assessment method was identical consisting of objectively structured questions from a departmental question-bank developed well ahead of the commencement of our study. Only the semester examination result of the Cardiovascular and Respiratory Physiology (two credit units) course was used. Students who were either repeating the course or were transferred into the department were excluded from the study population.

\section{Methods}

Lecture series: The group A had the traditional lecture series while Group B had a series of PBL exposures in addition to the traditional lectures. Two variants of PBL were used and are as outlined below:

i ) Diagnostic teaching: A set of questions are asked in the beginning of lectures to assess the pre-knowledge of students and to direct their thinking. Their ability to answer the question is subsequently reassessed after the lecture. An example of question asked before a respiratory lecture section is - a man after climbing a mountain was seen at the top with an increased respiratory rate; explain the physiology.

ii) Peer tutoring using problem-based learning: Groups of 15-20 students each had similar questions and assigned with a senior colleague as a facilitator and were to find answers to simple clinical questions like: a) Why would exercise increase blood pressure? Or b) a man slept-off with a small electric generator on and inside the same room, he was found dead in the morning. In what ways could the generator have contributed to the death? In the subsequent lecture, answers were discussed and debated and each student was to provide written answer with explanations.

\section{Statistical Analysis}

Student's attendance to lectures and examination scores were collated and analyzed using Microsoft excel software. The data was subsequently subjected to students' t-test for variance with significance set at a $\mathrm{P}$ level of 0.05 . 
Table 1: Students attendance and performance

\begin{tabular}{lcl}
\hline \multicolumn{1}{c}{ Indices } & $\begin{array}{c}\text { Traditional } \\
\text { lectures group } \\
(\mathrm{n}=126)\end{array}$ & $\begin{array}{c}\text { PBL Hybrid } \\
\text { lectures group } \\
(\mathrm{n}=168)\end{array}$ \\
\hline Class Attendance: & $40-78 \%$ & $42-87 \%$ \\
Range: & $62.7 \%$ & $76.8 \% * *$ \\
Mean: & & \\
Class Evaluation: & $61.9 \%$ & $72.0 \% * *$ \\
Total passes $(\geq 40 \%)$ & & \\
Total Failure (<40\%) & $38.1 \%$ & $28.0 \% * *$ \\
$\quad$ & & \\
Scores' Statistics: & $2-90 \%$ & $6-98 \%$ \\
Range & $48.6 \%$ & $60.2 \% * *$ \\
Average score & $68.3 \%$ & $45.3 \% * *$ \\
$\quad<50 \%$ & $31.7 \%$ & $55.7 \% * *$ \\
$\quad \geq 50 \%$ & & \\
\hline
\end{tabular}

** = Significant at $P \leq 0.05$

\section{Results}

The results are summarized in tables 1 and figures 1-3:

In general table 1 indicates a significant increase in attendance to lectures by hybrid model students (mean attendance rate $=72.8 \%$ ) compared to a mean attendance of $62.7 \%$ by the traditional learners group $(\mathrm{P}=0.012)$. This would suggest an increase in interest in the sessions.

There was also, an increase in number of students passing the semester examination for the course from $61.9 \%$ to $72.0 \%$ in favour of the hybrid model cohort $(\mathrm{P}=0.031)$. Similarly, more than half of the students $(55.5 \%)$ who had the hybrid model exceeded the $50^{\text {th }}$ percentile at the semester examination, compared with $31 \%$ in the traditional lecture cohort. Among the traditional learners' group $48.7 \%$ of those who passed the semester examination scored between $40-49 \%$, whereas $42.1 \%$ of those who passed among the hybrid model group scored between $50-59 \%$ (Figure 2).

Figure 2 also shows that $63.8 \%$ of candidates in the hybrid model group who failed in the semester examination failure scored between 30-39\% which differs significantly $(\mathrm{P}=0.013)$ from the performance of students from the traditional learners group at $41.7 \%$. This means that the relative performance of the candidates in the hybrid model who failed was comparatively better than that of the candidates form the traditional learners group.

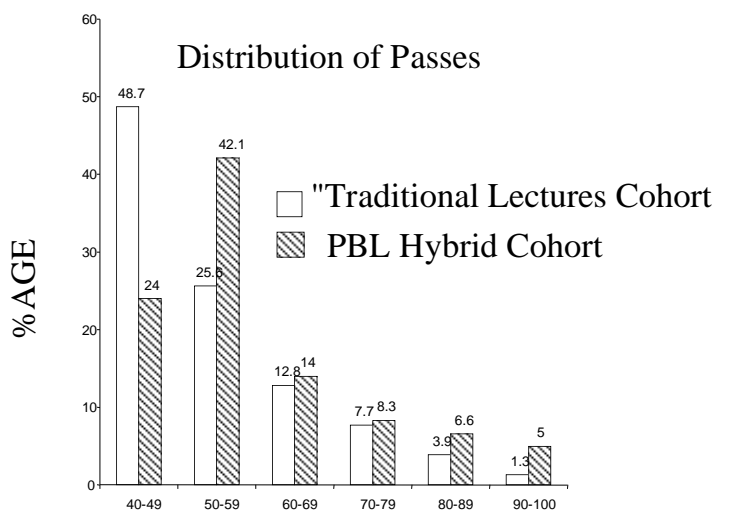

Scores

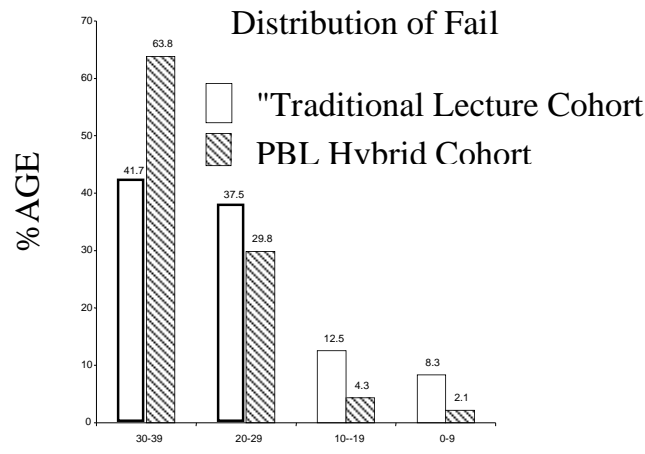

Scores in $\%$

Figure 1: Distribution of pass scores (>40\%)

Figure 2: Distribution of fail scores (<40\%) 


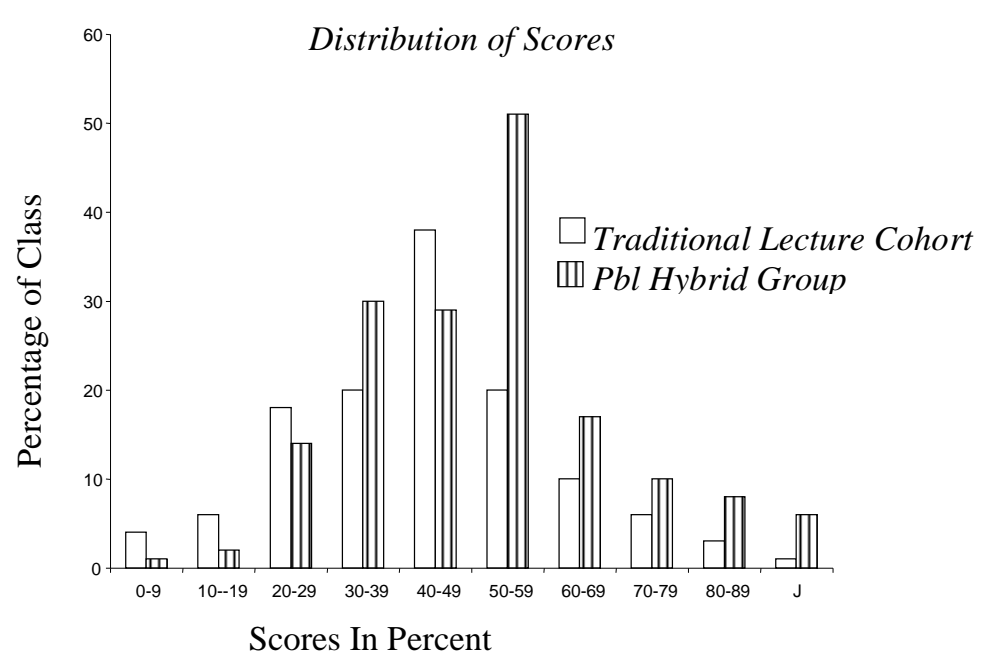

Figure 3: Distribution of scores

\section{Discussion}

Our report shows an increase in the attendance of students to lectures involving active-learning process (hybrid cohort) with a peak of $87 \%$ which exceeds the peak attendance of the $78 \%$ noted in the traditional learners group (Table 1). Also, the mean attendance to lectures by the hybrid cohort students is $76.8 \%$ which is significantly higher than the $62.7 \%$ attendance by the traditional lecture cohort. These findings are consistent with those of Lake (1999) who reported a peak attendance of $88 \%$ of students to peer tutored PBL sessions in addition to a willingness of upper level students to be involved in peer tutoring. The participation of the students in class as indicated by number of questions asked was remarkably increased, a finding in line with those of Walters (1999) report of increased students interest and participation in a similar approach which involved building case-stimulated learning problems into lectures to illustrate basic concepts covered in the lectures.

The hybrid (actively taught) students also had a significantly better performance in the semester examination when compared with the traditional lecture cohort/group with majority $(55.5 \%)$ above the $50^{\text {th }}$ percentile as against $31 \%$ in the traditional lecture cohort. The finding agrees with reports that students learn more in active learning environments (Cross, 1987) and that PBL offers potential benefit above traditional learning methods (Vernom 1993). The percentage of students above the $90^{\text {th }}$ centile also increased significantly from $1.0 \%$ in the traditional lecture cohort to $6.0 \%$ in the hybrid group. This finding agrees with the report that students that had PBL lectures did better in step 1 of United States Medical Licensing Examinations (USMLE) with over
$30 \%$ higher than $90^{\text {th }}$ percentile (Cunningham et $a l, 2001)$. This is in addition to reports from the clinical department that assert that they had more problem-solving skills and superior clinical reasoning (Barrows et al, 2001). Small group teaching has been well documented not only to increase retention of knowledge through improvement in both students interest and self directed learning (Rao and DiCarlo, 2000), but also enhances transfer of concepts to solving new problems (Norman and Schmidt, 1992). This may explain the better performance of the hybrid cohort.

A review of our data indicate that the PBL cohort group performed better than the traditionally taught group such that majority $(63.8 \%)$ of students that failed the course scored above the $30^{\text {th }}$ percentile when compared with $41.7 \%$ in the traditionally taught group (figure 2 ); also there was a significant increase in the average score (Table 1). These findings are significant and important considering that the PBL hybrid cohort had a larger class size; we thus speculate that their performance would have even fared much better comparatively if the classes were of same size numerically. It is thus valid to concur with Euliano (2001) that small group teaching and problem based learning offer greater advantages over the traditional didactic lectures.

Animal-based laboratory exercises in Physiology provide active learning experiences but, over time laboratory time has been reduced and there has been a gradual resistance to use of live animals (Genneth et al, 1992) plus existing funding difficulties in Nigerian universities.

Functional development of the brain and mind is both a biological and an active process depending on experiences; there is a need to actively involve the whole body and mind in successful learning. Our experience supports 
this because the interest of our students as well as their contributions in class increased demonstrably as evidenced either by questions asked or answers given. Meaningful learning and better understanding of Physiology can be enhanced by a hybrid of traditional lectures and PBL. It may require more effort and preparation on the part of the teacher, but this is more likely to occur if the teacher and managers of the system can clearly and explicitly define it as a major objective.

\section{Conclusion}

Physiology is an important body of knowledge for both medical and allied medical training. Laboratory exercises have been helpful in developing and validating workable mental models but for various reasons laboratory exposure is declining. There is thus a need for the design of effective learning environments to meet with changing goals and objectives of education. Students populations have not only increased but also changed over time, as well as society requirement. Thus there is a need for teaching methods that are both learner-centered and culturally sensitive (Committee on Development in the Science of Learning, 2004). Classrooms can be positively influenced by opportunities to interact created by teachers for learning and feedback. Active learning processes are becoming increasingly available to bridge these gaps in the developed world and it should be encouraged and sustained in Nigeria even as the world becomes a global village. Since a good percentage of our medical graduates end up in these developed countries they will benefit from similar learning environments.

\section{References}

APS Refresher Course Report (2001). Advances in Physiology Education. 25(3): 211-249.

Barrows, H. S. (1986). A taxonomy of problem based lecture methods. Medical Education 20: 481-486.

Barrows, H. S., William, R. G. and Mary, R. H. (2001). A comparative performance based assessment of $4^{\text {th }}$ year students clinical skills. $J$ Med. Educ. 62: 805-807

Barrows, H. S. and Tamblyn, R. M. (1980). Problem based learning, an approach to medical education. Springer, New York.

Committee on developments in the science of learning (2004). How people learn (expanded edition). National Academy Press, Washington D.C.

Received: $29 / 6 / 2007$

Accepted: 15/11/2007
Cross, P. K. (1987). Teaching for learning. Am Assoc Higher Educ Bull. 39:3-7.

Cunningham, J. T., Freeman, R. H. and Hosokawa, M. C. (2001). Integration of neuroscience and endocrinology in hybrid PBL curriculum. Advances in Physiology Education. 25(3):233240.

Dolmans, D. J. H. M., De Grave, W., Wolfhagen, I. H. A. P., Van der Vleuten, C. P. M and Winjnen, W. H. F. (2005). Problem based learning: future challenges for educational practice and research. Medical Education. 39: 732-741.

Euliano, Y. T. (2001). Small group teaching: clinical correlation with a human patient stimulation. Advances in physiology education. 25(1-4): 3643.

Genneth, S., Caston, D., Kindly, B. and Smith, J. (1992). Review of three decades of laboratory exercises in the preclinical curriculum at the Case Western Reserve University of Medicine. Acad. Med. 67: 203-206.

Lake, A. D (1999). Peer tutoring improves student performance in advanced physiology course. Advances in physiology education 21(1): S86S92.

Mennin, S. (2007). Small group problem-based learning as a complex system. Special edition of teaching and teacher education (in press)

Michael, J. (2001): In pursuit of meaningful learning; The Claude Bernard distinguished lecture 2001. Advances in Physiology Education. 25 (1-4); 145-158

Neufeld, V. R., Woodward, C. A. and Macleod, S .M. (1989). The Mc Master M.D. program; a case study of renewal in medical education. Acad. Med. 64:423-432

Norman, G. R. and Schmidt, H. C. (1992). The psychological basis of problem based learning, e review of evidence. Acad. Med. 67:557-565

Nshaho, J. (2005). Innovative strategies in teaching biomedical sciences to health sciences. Nigerian Journal of Physiological Science. 20(1-2): 8-10.

Nwobodo, Ed. (2005). Paper presented at a workshop on curriculum development at the College of Medicine, university of Nigeria, Enugu campus.

Palinscar, A. S. and Brown, A. L (1984) Reciprocal teaching of comprehension monitoring activities cognition and instruction. 1: 117-175.

Rao, S. P. and DiCarlo, S. E. (2000). Peer instruction improves performance on quizzes. Adv. Physio. Educ. 24: 51-55.

Vernom, D. T. A and Blake, R. L. (1993). Does problem based learning work? A meta-analysis of evaluation of research. Academic Medicine. 68: 550-563.

Walters, M. R. (1999). Case stimulated learning within endocrine physiology lectures: An approach applicable to other disciplines. Advances in Physiology Education. 21(1); S74S78. 